\title{
NOTAS SOBRE LA SITUACION JURÍDICA DE LA MUJER EN EL FRANQUISMO
}

\author{
Mangeles Moraga GarcíA \\ Universidad de Alicante
}

Fecha de recepción: 03-11-2008.

Fecha de aceptación: 26-11-2008.

\section{Antecedentes: la segunda República Española}

Para entender hasta qué punto el Franquismo resultó nefasto para las mujeres, es preciso conocer cuál fue la situación en el período histórico inmediatamente anterior al triunfo del golpe de estado y la instauración de la dictadura fascista. Para ello, vamos a esbozar, mínimamente, el marco constitucional de la Segunda República Española en materia de igualdad, y las consecuentes reformas legislativas que se produjeron en este período a favor de los derechos de las mujeres.

La Constitución de la República Española de 1931 supuso un punto de inflexión en la historia jurídica de nuestro país, en cuanto que reconoció, por primera vez, la igualdad jurídica entre mujeres y hombres. Dicho principio se recogió en su artículo 25, en el que se declaraba expresamente que «No podrán ser fundamento de privilegio jurídico, la naturaleza, la filiación, el sexo, la clase social, la riqueza, las ideas políticas ni las creencias religiosas».

Como consecuencia de ello, por lo que respecta a los derechos políticos, el artículo 36 reconocía -por primera vez- el derecho de voto a la mujer, estableciendo que: «Los ciudadanos de uno y otro sexo mayores de 23 años tendrán los mismos derechos electorales conforme determinen las leyes». Pero dicho reconocimiento del derecho de sufragio para las mujeres no fue ni mucho menos pacífico, por el contrario, sólo se alcanzó tras un encarnecido debate que tuvo lugar en las Cortes Constituyentes de la Segunda Republica, y se consiguió gracias a la tenacidad de una valiente Diputada, Clara 
Campoamor ${ }^{1}$. La mayoría de los parlamentarios de los partidos progresistas mostraban su recelo a la concesión del voto femenino, al considerar que éste sería de derechas y por ello se oponían a otorgar dicho derecho a las mujeres, lo cual, como señala la Profesora Asunción Ventura, sólo venía a demostrar «una cierta actitud misógina, ya que no consideraban a la mujer capaz de decidir por sí misma, y por la creencia que todas ellas responderían por igual ante el hecho electoral, como si no existieran intereses distintos entre ellas -obreras, empleadas, aristócratas, burguesas, etc.-»².

Por otra parte, en el ámbito del derecho privado, el artículo 43 reconocía la igualdad de derechos de ambos sexos en el matrimonio, así como la disolución del mismo a petición de cualquiera de los cónyuges alegando justa causa, lo que permitió instaurar el divorcio a través de la Ley de 2 de marzo de 1932, en la que se establecía la igualdad de los hijos, desapareciendo la distinción entre hijos legítimos e ilegítimos, se adoptaba el termino «autoridad del padre y de la madre», frente a la clásica autoridad paterna, y se aceptaba el mutuo consentimiento para obtener el divorcio. De esta forma, durante los años 1932 y 1933, del total de demandas de divorcio que se formularon, un $56 \%$ fueron presentadas por mujeres, frente al $43 \%$ que lo fueron por varones. Y las principales causas que se alegaban para solicitar el divorcio, eran: la separación por más de tres años, el desamparo, el abandono, los malos tratos y la conducta inmoral ${ }^{3}$. Dicha norma fue seguidamente complementada por la Ley de 28 de junio de 1932 que vino a implantar el matrimonio civil.

Por lo que respecta al ámbito profesional, el artículo 40 de la Constitución de 1931 reconocía a las mujeres el legítimo derecho a ejercer una profesión, señalando expresamente que «Todos los españoles, sin distinción de sexo, son admisibles a los empleos y cargos públicos según su mérito y capacidad, salvo las incompatibilidades que las leyes señalen». Y ello no sin la oposición de numerosos detractores a la incorporación de la mujer al mundo laboral, que alegaban como motivos de su oposición, sobre todo razones biológicas y de cumplimiento de las obligaciones familiares, tales como el cuidado del

1. Fue una de las tres únicas diputadas elegidas en las Cortes Constituyentes de 1931, por el partido Radical. Electa en la primera vuelta por la circunscripción de Madrid Provincia. Resulta muy interesante la lectura de su libro titulado Mi pecado mortal. El voto femenino y yo, Madrid, Beltrán, 1939.

2. Ventura Franch, Asunción: Las Mujeres y la Constitución Española de 1978, Madrid, Ministerio de Trabajo y Asuntos Sociales, Instituto de la Mujer, 1999, p. 83.

3. Estadísticas de divorcios y separaciones, Madrid, Ministerio de Justicia, 1936, en el articulo de MORCILlO GÓMEZ, Aurora: «Feminismo y lucha política durante la II Republica y la Guerra Civil», en la obra Femimismo en España. Dos siglos de historia, coord. por FOLGUERA, Pilar, Ed. Pablo Iglesias, 2007, p. 68-69. 
marido, hogar e hijos. Pero lo cierto es que a consecuencia de dicho reconocimiento constitucional, se permitió a las mujeres acceder a empleos que hasta entonces tenía vedados, tales como notarias y registros de la propiedad, a partir del Decreto de 29 de abril de 1931, cuerpo diplomático y secretarios municipales, tras la aprobación del Decreto de 13 de mayo de 1931, o Procurador de los Tribunales por el Decreto de 6 de mayo de 1933.

Este nuevo marco constitucional impulsó importantes reformas legales, además de las ya expuestas, que mejoraron la situación jurídica de las mujeres. Así, por ejemplo, el Código Penal de 1932 suprimió el delito de adulterio, no reconociendo ya desde ese momento el derecho del marido a matar a los adúlteros, ni el del padre de matar a su hija y al corruptor. Y por su parte, el Decreto de 28 de junio de 1935 suprimió la reglamentación de la prostitución, anulándola como medio lícito de vida.

Todo ello permitió a las mujeres mejorar su condición de ciudadanas, ya que por primera vez se les reconocieron derechos hasta entonces vedados y se alcanzaron cotas de presencia y participación en la vida social y política hasta entonces nunca logradas ${ }^{4}$.

\section{El golpe de estado militar y la instauración del régimen franquista}

Sin embargo, la situación descrita anteriormente apenas duró un lustro. Ya que el golpe de estado militar y la Guerra Civil dieron paso al triunfo del Régimen Franquista que supuso una profunda regresión en el camino de la igualdad, devolviendo a la mujer al rol tradicional, de esposa y madre, suprimiendo todos los logros obtenidos durante los años que había durado la Segunda Republica.

El Régimen va a devolver a la mujer al ámbito doméstico, encomendándole las «sagradas» funciones de fortalecer la familia, educar a los hijos en la fe cristiana y en la doctrina falangista, potenciar la tasa de natalidad, y ser el refugio y descanso del esposo.

Resultaba lógico pensar que el establecimiento de un régimen dictatorial de corte fascista, sin duda comportaría una serie de limitaciones y negación de derechos para todas las personas. Pero lo cierto es que éste incidió de una

4. En el interesante libro dirigido por la profesora Julia SEVILLA MeRINo, Las mujeres parlamentarias en la legislatura constituyente (Cortes Generales. Ministerio de la Presidencia, 2006, p. 10), se afirma que «Si nos fijamos en España observamos cómo el movimiento feminista no existió hasta bien entrado el siglo XX y cristalizó con la Constitución Republicana de 1931, que, con el reconocimiento del sufragio femenino, introduce en la sociedad patriarcal española la relevancia del papel de la mujer».

Feminismo/s 12, diciembre 2008, pp. 229-252 
manera especialmente significativa en las mujeres, suponiendo para ellas la vuelta a la subordinación jurídica y representado un retroceso de siglos ${ }^{5}$.

La dictadura estableció de inmediato una serie de medidas destinadas a reposicionar a la mujer en una situación de sometimiento. Todos los avances logrados desaparecieron casi de un plumazo. Así, por ejemplo, se suprimió la escuela mixta, se prohibió el trabajo nocturno a mujeres, se «liberó» a la mujer casada «del taller y de la fábrica». Igualmente se les prohibió el acceso al ejercicio de profesiones liberales y otros empleos dentro de la función pública, tales como Abogados del Estado, Registradores de la Propiedad, Cuerpo Diplomático, Jueces, Magistrados, etc. Todo ello acompañado de una política de concesión de primas por maternidad y subsidios familiares, siempre abonables al «jefe de la familia».

Asimismo, se derogó la ley del matrimonio civil y la ley de divorcio con efectos retroactivos, se penalizó el aborto, el adulterio y el concubinato. También se incrementó la mayoría de edad a los 25 años, obligando a la mujer joven a permanecer en el hogar paterno hasta el momento de casarse o entrar en un convento.

Con todo ello se consolidó un modelo de familia como célula primaria, natural y fundamento de toda sociedad, correspondiéndole a la mujer el rol de esposa y madre, y por lo tanto, entre sus funciones estaba la de educar a los hijos en la fe cristiana y en la doctrina falangista, y ser el refugio y descanso del marido.

A partir de dichas premisas, el Estado franquista elaboró toda una legislación patriarcal, sustentada en la autoridad del padre/marido y totalmente discriminatoria para las mujeres. Con ello, nuestro país se convirtió en un ejemplo del más puro estilo de patriarcado, en el que las mujeres quedaron relegadas a una posición de subordinación que las recluía en el ámbito doméstico.

Esta situación jurídica, claramente desigualitaria para la mujer, se prolongó durante los cuarenta años de la dictadura, sin apenas modificaciones. La razón que mantuvo esta discriminación de la mujer, enlaza con la esencia ideológica del régimen convencido de que España era la «reserva espiritual de Occidente», y que por tanto debía de mantenerse la función sagrada que dicho régimen reservaba a las mujeres, de guardianas del hogar y de los valores tradicionales.

5. Rosalía SENDER BEGUÉ (Luchando por la liberación de la mujer, Valencia, 1969-1981, Universitat de Valencia, 2006, p. 182) afirma que «Tras la Guerra Civil, nosotras las mujeres perdimos más que los hombres, porque además de la libertad y la democracia, Franco nos arrebató todos los derechos que la República nos otorgó y que situaban a la mujer española en la vanguardia de Europa». 
Precisamente el adoctrinamiento de las mujeres, se realizó a través de una organización de composición exclusivamente femenina, denominada Sección Femenina de Falange Española, primero, y Sección Femenina del Movimiento, después, que se convirtió en el instrumento de control y de difusión ideológica del Régimen ${ }^{6}$.

La principal tarea de dicha organización consistía en controlar la educación que recibían las mujeres en las escuelas, enseñanza basada en la sumisión y en la inferioridad, prolongando esta formación una vez concluido el período de la educación obligatoria mientras la mujer permaneciera soltera hasta el momento cumbre de su vida, el matrimonio, todo ello cargado de un fuerte componente religioso. La Sección Femenina se encargó, por tanto, de la educación social, política y doméstica de todas las jóvenes y mujeres a lo largo de la existencia del régimen ${ }^{7}$.

Dicha organización se convirtió en la correa de transmisión de los valores morales y políticos del régimen de Franco, desarrollándose como un instrumento de éste para la divulgación ideológica y de control de las mujeres, con el objetivo de garantizar el cumplimiento de la misión que el régimen les había reservado, ya que el fin natural de toda mujer debía ser el matrimonio, y por tanto dicha organización tenía como objetivo devolver a las mujeres a sus funciones tradicionales en la sociedad. Lo que pregonaba la Sección Femenina era un «feminismo» basado en la obediencia y en la sumisión de la mujer al hombre.

Para ilustrar este punto, a continuación se reproducen algunos textos de Pilar Primo de Rivera, hermana del fundador del partido fascista de la Falange, que a su vez ostentaba el cago de Jefe Nacional de la Sección Femenina, en los que se constatan los principios ideológicos que sustentaron la subordinación jurídica de la mujer durante la dictadura franquista:

Hay que volver a poner al hombre los pies sobre la tierra. Y para la mujer la tierra es la familia. Por eso, además de darles a las afiliadas la mística que las eleva, tenemos que apegarlas con nuestras enseñanzas a la labor diaria, al hijo, a la cocina, al ajuar, a la huerta, tenemos que conseguir que encuentre allí la mujer toda su vida y el hombre todo su descanso ${ }^{8}$.

6. Magnífico el estudio que se realiza sobre la Sección Femenina en el libro Mujer, Falange y Franquismo (Madrid, Taurus, 1983) de $\mathrm{M}^{a}$ Teresa GALLEGO MÉNDEZ.

7. Resulta muy interesante la obra de RichAMOND, Kathleen y otro: Las mujeres en el fascismo español: La Sección Femenina de la Falange, 1934-1959, Madrid, Alianza Editorial 2004, donde se examina la base ideológica de la Sección Femenina, y también se analiza la aportación de la Sección Femenina a la legislación, la prosperidad económica y el tejido social de España durante ese periodo.

8. Primo De Rivera, Pilar: Escritos, Circulares, Discursos, Madrid, s/f, p. 28.

Feminismo/s 12, diciembre 2008, pp. 229-252 
La base principal de los estados es la familia, y por tanto el fin natural de todas las mujeres es el matrimonio. Por eso la Sección Femenina tiene que prepararlas para que cuando llegue ese día para ellas, sepan decorosamente dirigir su casa y educar a sus hijos conforme a las normas de la Falange, para que así, transmitidas por ellas de una en otra generación llegue hasta el fin de los tiempos ${ }^{9}$.

De esta manera, señalaba Pilar Primo de Rivera, «Metidas en casa habréis hecho más que todos los discursos» ${ }^{10}$.

En torno a la abnegación, dice: «Es sin duda nuestro movimiento el que en cierto aspecto esencial asume mejor un sentido femenino de la existencia. En su espíritu de abnegación, abnegación que significa renuncia a las satisfacciones sensuales en homenaje a un orden superior».

Y del silencio: «Todos los días debíamos dar gracias a Dios por habernos privado a la mayoría de las mujeres del don de la palabra, porque si lo tuviéramos quién sabe si caeríamos en la vanidad de exhibirlo en las plazas» ${ }^{11}$.

En esta misma línea, se había expresado ya José Antonio Primo de Rivera, fundador de la Falange e ideólogo del Régimen en el año 1935, en un mitin celebrado en Don Benito, pueblo de la provincia de Badajoz, en el que éste pronunció sus primeras y únicas palabras referidas a la mujer, de las que posteriormente se nutrió el ideario de la Sección Femenina.

Tampoco somos feministas. No entendemos que la manera de respetar a la mujer consista en sustraerla a su magnifico destino y entregarla a funciones varoniles....

El hombre... es torrencialmente egoísta, en cambio, la mujer casi siempre acepta una vida de sumisión, de servicio, de ofrenda abnegada a una tarea.

El verdadero feminismo no debiera consistir en querer para las mujeres las funciones que hoy se estiman superiores, sino en rodear cada vez de mayor dignidad humana y social a las funciones femeninas ${ }^{12}$.

En estos textos se concreta el modelo de mujer para el Franquismo, hacendosa, abnegada y sumisa, y que en ningún caso debía intentar igualarse al hombre, que era considerado un ser superior.

9. PRIMO DE RIVERA, Pilar: Misión y organización de la Sección Femenina de FET y JONS, Madrid, 1942.

10. PRIMO DE RIVERA, Pilar, en Escritos...op. cit, p. 35.

11. PRIMO DE RIVERA, Pilar, Escritos..., op. cit, p. 36.

12. Textos recogidos en PRIMO DE RiverA, José Antonio: Obras Completas. Tomo I, Discursos Fundamentales y otros Discursos de Propaganda; Madrid, FET y de las JONS, pp. 179-183. 


\section{Situación jurídica de las mujeres durante la dictadura franquista}

Esta concepción ideológica de la mujer en el período franquista jugó un papel decisivo en lo que respecta a su situación jurídica, que vamos seguidamente a analizar en cuatro grandes ámbitos: el Derecho de Familia, el Derecho Penal, el Derecho a la Educación y el Derecho del Trabajo:

\subsection{Derecho de familia}

El franquismo acabó con todos los avances que en el ámbito del derecho privado se habían alcanzado durante el período republicano. Así, mediante la aprobación de la Ley de 12 de marzo de 1938, se declaró la vigencia del Titulo IV del Libro I del Código Civil de 1889, que había sido derogado durante la Segunda República, una norma que era claramente discriminatoria para la mujer, al consagrar su discapacidad jurídica como principio general.

Asimismo mediante la referida Ley de 12 de marzo de 1938 se derogó la Ley de 28 de junio de 1932, lo que supuso la abolición del matrimonio civil, así como todas las inscripciones hechas en el Registro Civil, con efectos retroactivos.

Por su parte, la Ley de 23 de septiembre de 1939 derogó la Ley de divorcio de 1932, y con ello los logros que a través de dicha norma se habían alcanzado. Evidentemente, no podía caber en la construcción jurídica civil del franquismo una figura que consagraba la igualdad jurídica de los cónyuges, y que otorgaba a la mujer el estatus de persona adulta emancipada de toda tutela.

Adicionalmente, las leyes franquistas asimilaban la familia al matrimonio legalmente constituido (canónico, claro), de tal forma que sólo se prestaba protección jurídica a aquellas familias legalmente reconocidas. Frente a ellas, cualquier otra forma de relación familiar, no legitimada, no sólo estaba excluida de cualquier protección, sino que en muchos casos llegaba a estar penalizada (p. eje. los supuestos de adulterio).

Pero además, la consecuencia de este régimen recaía directamente en los hijos, que, según hubieran sido engendrados dentro o fuera del matrimonio, gozaban de más o menos derechos, siendo el régimen de filiación totalmente arcaico y discriminatorio, al relegar el Código Civil a los hijos ilegítimos, y no admitir la investigación de la paternidad.

La familia, por tanto, era el destino natural para las mujeres. Pero, toda familia estaba gobernada por un cabeza de familia: el marido, quien ostentaba la autoridad dentro del ámbito familiar. Él era quien podía hacer y deshacer de acuerdo con lo que consideraba más oportuno. Además el Estado, le reconocía como el único interlocutor válido entre la familia y la sociedad. Tal es así, que la mujer, cuando pasaba a formar parte de la familia, pasaba también 
a depender de la potestad del marido, como antes dependía de la potestad de su padre.

En consecuencia con ello, la mujer tenía prohibido ejercer la patria potestad de sus hijos, ostentando sólo una patria potestad subsidiaria, en defecto de padre, según disponía el artículo 154 del Código Civil. Hasta tal punto se le privaba de la patria potestad, que el padre podía llegar a dar a sus hijos en adopción sin consentimiento de la madre, mientras que la mujer tenía prohibido adoptar por sí sola.

Incluso en el caso de que la mujer enviudara y contrajera matrimonio posteriormente, perdía la patria potestad sobre los hijos del matrimonio anterior, salvo, que su difunto esposo (padre de los hijos) hubiera dispuesto en el testamento la autorización para que su viuda contrajera posteriores nupcias, estableciendo que en tal caso conservaría la patria potestad sobre sus hijos.

La situación de desigualdad jurídica entre los cónyuges era muy evidente. Pero es que además, por si fuera poco, existía la llamada licencia marital, que obligaba a la mujer casada bajo régimen de gananciales -que era el que regía en el derecho común- a que solicitara la autorización de su marido para la realización de diversos actos. Como por ejemplo, para abrir una cuenta corriente, solicitar un pasaporte, firmar una escritura pública o cualquier tipo de contrato. Incluso con respecto a la disposición de sus bienes propios, la mujer casada necesitaba la autorización marital.

La mujer, sin la referida licencia marital, no tenía capacidad para ser albacea, ni tutora. Ni tampoco, sin dicho permiso, podía aceptar herencias ni solicitar su partición.

Tampoco podía sin dicha autorización marital ejercer actividades comerciales, a tenor de lo dispuesto en los artículos 6 a 9 del Código de Comercio. $\mathrm{Ni}$ tan siquiera realizar pagos en obligaciones de dar.

Pero resulta de importancia destacar que dicha licencia marital no fue derogada hasta la aprobación de la Ley 14/1975, de 2 de mayo, es decir, que estuvo vigente durante toda la Dictadura Franquista, hasta pocos meses antes del fallecimiento del dictador.

Además, el marido ostentaba la representación de su mujer, lo que suponía que ésta no pudiese comparecer por si misma en juicio, ni tampoco designar abogado o procurador que la representase, ni tan siquiera para defender sus propios intereses ${ }^{13}$.

13. El Artículo 60 del Código Civil disponía que: «El marido es el representante de su mujer. Esta no puede, sin su licencia, comparecer en juicio por sí o por medio de Procurador». 
También las relaciones patrimoniales entre los cónyuges se sustentaban en la discriminación de la mujer, ya que la mujer carecía incluso del derecho de administración y disposición de su propio patrimonio, lo que conllevaba una subordinación total al marido.

Una vez contraído el matrimonio bajo el régimen de gananciales, ya no se podía modificar éste. Y el artículo 1.413 del Código Civil atribuía al marido la facultad de enajenar a título oneroso los bienes de la sociedad de gananciales, ya que dicho texto legal, además de otorgarle la representación legal de su esposa, le encomendada la administración de los bienes de la sociedad conyugal.

La mujer estaba además sometida a la tutela del marido y obligada unilateralmente a obedecerle, al disponer expresamente el artículo 57 del Código Civil que «el marido debe proteger a la mujer y esta obedecer al marido».

Pero a la mujer no sólo le pesaba el deber de obediencia a su marido, sino que además venia obligada a adoptar su nacionalidad, a tenor de lo dispuesto en el Decreto de 2 de mayo de 1938. Y asimismo, de acuerdo con lo dispuesto en el articulo 58 del Código Civil, estaba obligada a seguir el domicilio de su cónyuge, allá donde éste fijase su residencia ${ }^{14}$.

Pero por si fuera poca la desigualdad jurídica que sufría la mujer casada, en el supuesto de que se produjera la separación de los cónyuges, al ser considerado el domicilio conyugal como «la casa del marido», la mujer era «depositada», viéndose obligada a salir de la casa, llevándose únicamente consigo la cama, la ropa de uso diario y a los hijos menores de tres años. Una vez dictada sentencia en el proceso de separación, el culpable perdía los hijos, pero la mujer perdía, además, la administración de los bienes parafernales que hubiese entregado al marido en escritura pública, la dote y la mitad de sus gananciales, que conservaba el marido en administración como si fueran dotales, pudiendo ella reclamar sólo el derecho de alimentos.

Por el contrario, el Código Civil dispensaba un mejor trato a la mujer soltera, quien una vez alcanzada la mayoría de edad, fijada en los veinticinco años, gozaba de plena capacidad de obrar, aunque con ciertas limitaciones, como la prohibición de abandonar la casa paterna sin su permiso, a no ser para tomar estado, o cuando éste hubiese contraído ulteriores nupcias; o la de

14. Artículo 58 del Código Civil: «La mujer está obligada a seguir a su marido donde quiera que fije su residencia. Los Tribunales, sin embargo, podrán con justa causa eximirla de esta obligación cuando el marido traslade su residencia a ultramar o a país extranjero». Esta restricción no desapareció hasta la aprobación de la Ley 14/1975, de 2 de mayo.

Feminismo/s 12, diciembre 2008, pp. 229-252 
ejercer la patria potestad sobre sus hijos naturales si el padre los había reconocido, aunque tenía que cargar con el reproche social de no tener un marido ${ }^{15}$.

Pero la tímida evolución ideológica del régimen, los cambios que se fueron produciendo en la sociedad española, los avances del derecho comparado en materia de igualdad y un cierto debate social, originaron diversas reformas en la legislación civil, que supusieron algún avance para las mujeres.

La primera modificación importante del Código Civil, tuvo lugar con la aprobación de la Ley de 24 de abril de 1958, la cual vino a ampliar la capacidad jurídica y de obrar de la mujer.

La reforma más importante que efectuó dicha Ley fue la del artículo 1413 del Código Civil añadiendo el «consentimiento uxoris» para la enajenación o gravamen de los bienes gananciales, limitando el omnímodo poder del marido y en especial la facultad de disposición que éste tenía sobre los bienes gananciales.

Asimismo, tras dicha reforma, se permitió a la mujer casada ser albacea y ocupar cargos tutelares, aunque se le seguía exigiendo para ello la autorización del marido, a tenor de lo dispuesto en el numero 7 del articulo 237 del Código Civil.

También se sustituyó la consideración que tenía la vivienda familiar como «casa del marido» por la de «hogar conyugal». Y a consecuencia de ello, en caso de separación, y en interés de la familia, se contemplaba la posibilidad de que la mujer continuase en el disfrute del domicilio conyugal, en la fase de medidas provisionales, y mientras durase el procedimiento judicial y recayera sentencia.

Incluso tras la reforma producida por la Ley de 1958, a la mujer que era considerada «culpable» en caso de separación, se le reconocía el derecho a administrar sus bienes propios y la mitad de los gananciales.

También se eliminó la perdida de la patria potestad de sus hijos para la viuda que contrajese nuevas nupcias (articulo 168 del Código Civil).

Otra importante modificación fue la eliminación del llamado «depósito de la mujer», por el cual, en caso de petición de separación o de nulidad matrimonial, la esposa debía ser «depositada» en casa de sus padres, en un

15. En ENCISO VIANA, Emilio: Muchacha, 1940, se llegaba a afirmar que «La soltera por virtud, cumple su misión femenina en las obras de apostolado, de beneficencia, sociales, patriótica, religiosas» ... «En nuestra guerra, en las diversas organizaciones femeninas, multitud de las llamadas solteronas han prestado servicios valiosísimos», «Pero, la soltera por egoísmo, porque, teniendo medios de vida, es mas cómoda la soltería, es una desequilibrada, exaltada, extravagante y no requiere ninguna atención porque no lo merece y no creo que ninguna de mis lectoras pertenezca a esta categoría». 
convento, etc. A partir de entonces el juez podía adjudicarle incluso el uso de la vivienda conyugal.

Pero dicha Ley sin embargo, no suprimió la licencia marital para la mujer casada, por entender que ésta reflejaba, según señalaba la propia Exposición de Motivos: «la posición peculiar de la mujer casada en la sociedad conyugal en la que, por exigencias de la unidad matrimonial, existe una potestad de dirección que la naturaleza, la Religión y la Historia atribuyen al marido».

Otras dos reformas importantes en materia de Derecho Civil, se produjeron con la aprobación de la Ley de 4 de julio de 1970, que eliminó la posibilidad de que el padre diese en adopción a los hijos sin el consentimiento de la madre; y con la Ley de 22 de julio de 1972, que, por una parte, fijó la mayoría de edad en los veintiún años para ambos sexos; y además permitió a las hijas mayores de edad, pero menores de veinticinco años, abandonar la casa paterna sin su permiso y sin necesidad de contraer matrimonio o ingresar en un convento.

Pero el logro más importante en esta materia no se produjo hasta finales de la Dictadura, en concreto en el año 1975, que fue declarado por la Organización de las Naciones Unidas, Año Internacional de la Mujer.

Fue precisamente en ese año cuando se aprobó la Ley 14/1975, de 2 de mayo, que supuso un avance importante al reformar diversos artículos del Código Civil y del Código de Comercio que afectaban a la situación jurídica de la mujer casada y a los derechos y deberes de los cónyuges. En concreto se reformaron cincuenta y nueve artículos del Código Civil y otros nueve del Código de Comercio.

Los puntos principales de la reforma fueron los relativos a la nacionalidad, el régimen económico dentro del matrimonio y la capacidad de obrar en el orden jurídico.

A partir de la entrada en vigor de la reforma efectuada por la referida Ley $14 / 75$, la mujer casada ya no perdía su nacionalidad al casarse con un extranjero.

Además, dicha norma suprimió la limitación que durante tantos años habían sufrido las mujeres casadas, la licencia marital, vigente hasta ese momento, al reconocer en el artículo 62 que «El matrimonio no restringe la capacidad de obrar de ninguno de los cónyuges» y estableciendo en el precepto siguiente, 63, que ninguno de los cónyuges podía atribuirse la representación del otro.

Ello conllevó también la modificación de otros preceptos, como el artículo 1387 del Código Civil, que hasta la reforma impedía a la mujer, sin licencia de su marido, disponer de los bienes parafernales, ni siquiera comparecer en 
juicio para litigar sobre ellos, mientras que tras la reforma introducida por la Ley 14/75 en el referido precepto, se habilita a la mujer para disponer por sí sola de sus bienes propios. Y a continuación, tras la reforma efectuada en el artículo 1388, se autoriza también a la mujer para comparecer en juicio y litigar sobre los bienes parafernales.

Asimismo en el nuevo texto, el deber de obediencia de la mujer al marido, previsto en el artículo 57 del Código Civil, quedó eliminado, disponiendo en su lugar que «el marido y la mujer se deben respeto y protección recíprocos, y actuarán siempre en interés de la familia».

Además se recogió algo que los regímenes forales ya tenían, como era la posibilidad de poder pactar capitulaciones matrimoniales después de celebrado el matrimonio.

Por lo que respecta a las reformas efectuadas al Código de Comercio, se eliminaron las trabas de la mujer casada para celebrar contratos, así como para ejercer actividades mercantiles, al suprimirse la licencia marital.

Esta Ley supuso por lo tanto un avance considerable en la posición jurídica de la mujer en el ámbito del derecho civil; pero sin embargo el Código Civil seguía conservando importantes lastres para la mujer, como por ejemplo, el mantener la preferencia del marido sobre la mujer respecto a la atribución de la patria potestad de los hijos, o el atribuirle a éste la exclusiva administración de los bienes matrimoniales.

\subsection{Derecho Penal}

El franquismo controló y reprimió con especial energía todo lo relacionado con el comportamiento sexual de las personas, y especialmente de las mujeres.

La religión católica impregnaba todo el derecho, incluido, cómo no, el derecho penal, y por lo tanto la norma se utilizaba para moralizar, orientándose hacia la represión y no hacia la protección de los derechos de los ciudadanos, y mucho menos de las mujeres.

Las leyes penales franquistas asimilaban las mujeres a los incapaces y además sólo daban protección a las mujeres que eran consideradas «honestas», ya que si no lo eran, eran tratadas como un simple objeto, a disposición del varón, quien podía incluso llegar a violar a su mujer sin temor a ser sancionado penalmente.

En esta materia todo giraba, por tanto, alrededor del honor y de la honra; pero, bien entendido que lo que se estaba protegiendo era el honor del marido y del padre, no el de la mujer. 
La promulgación del Código Penal de 1944 supuso, en relación con la normativa anterior, un claro y duro empeoramiento de la situación jurídica de la mujer.

En dicho Código Penal se incluyó entre los tipos penales, el llamado «uxoricidio por causa de honor», que había suprimido el Código republicano. Este delito de uxoricidio constituía un auténtico privilegio concedido al hombre en defensa de su honor, en virtud del cual podía matar o lesionar a la esposa sorprendida en flagrante adulterio o a la hija menor de veintitrés años, mientras viviere en la casa paterna, cuando fuere sorprendida en análogas circunstancias.

Asimismo en dicho Código se volvía a recoger el tipo penal de adulterio, pero sólo para la mujer, ya que para el hombre el tipo delictivo era distinto: el amancebamiento. Se retrocedía respecto a la legislación penal anterior, ya que el Código Penal de la República no consideró delito el adulterio, ni para el hombre ni para la mujer, puesto que la ley de divorcio existente en la época republicana consideraba la infidelidad como causa de disolución del matrimonio y por lo tanto no merecía reproche penal alguno.

Pero la Ley de 11 de mayo de 1942 vuelve a considerar punible tanto el adulterio como el amancebamiento, y así pasa al Código Penal de 1944, el cual en su artículo 449 disponía que «cometen adulterio la mujer casada que yace con varón que no sea su marido y el que yace con ella sabiendo que es casada, aunque después se declare nulo el matrimonio». Mientras que por lo que respecta al hombre, el artículo 452 disponía que para que hubiese delito hacía falta que «El marido tuviera manceba dentro de la casa conyugal o notoriamente fuera de ella». A la mujer, por lo tanto, se la castigaba porque yaciese una sola vez con varón que no fuese su marido, aunque existiese separación de hecho del marido, mientras que esta misma conducta realizada por el hombre no resultaba punible, ya que para que lo fuera hacia falta permanencia y habitualidad. Esto evidencia la desigualdad jurídica de trato que el Código Penal dispensaba a las mujeres.

Dicho Código Penal tipificaba además los llamados delitos contra la honestidad, donde se recogían los delitos de violación, abusos deshonestos, escándalo publico, estupro, corrupción de menores, rapto y delitos relativos a la prostitución, aunque evidentemente el bien jurídico que se protegía a través de dichas figuras delictivas no era la libertad sexual de la mujer, sino el honor, personal y familiar.

Debido precisamente a esta consideración, si la violencia sexual se ejercía dentro del matrimonio no merecía reproche penal alguno. 
Asimismo, el Código Penal también castigaba el aborto, tanto a quien lo causaba como a la mujer que consentía que se lo realizaran, salvo que el aborto se produjera para ocultar la deshonra, en cuyo caso la pena a imponer era menor. También en dicha norma penal, se penalizaba expresamente el uso de los anticonceptivos.

Resulta también interesante destacar que en el tipo penal de infanticidio honoris causa la muerte del hijo recién nacido que ha sido ilegítimamente concebido, cometido por la madre o por los abuelos maternos para ocultar su deshonra, la pena se rebajaba atendiendo a que el móvil del delito era ocultar la deshonra. Pero sólo podía apreciarse dicho tipo penal cuando la mujer era soltera, viuda o casada, siempre que fuese honesta, pues en otro caso el delito era calificado de parricidio.

A todo lo anterior hay que añadir que el Código Penal disponía que si mediaba el perdón de la ofendida se extinguía la acción penal, y por lo tanto, toda responsabilidad hasta el punto de que el violador podía eludir la cárcel si obtenía el perdón de la víctima o si la llevaba ante el altar.

Y no fue hasta bien avanzada la Dictadura, cuando se empezaron a realizar algunas reformas al Código Penal. Así, el Decreto de 21 de marzo de 1963, que vino a eliminar del Código Penal la facultad que se concedía a padres y maridos de matar a sus hijas o esposas y a los hombres que con ellas yacían cuando eran cogidos en fragrante adulterio, la llamada «venganza de sangre».

\subsection{Derecho a la Educación}

La religión y moral católica impregnó el modelo educativo durante el franquismo.

Ya en los primeros años del Régimen, se aprobaron medidas con el propósito de destruir la legislación que sobre esta materia había sido aprobada durante la Segunda República, en la que se había implantado una educación laica, obligatoria y coeducativa ${ }^{16}$. Pero, fue la Ley de 20 de septiembre de 1938 la que definitivamente consolidó el modelo conservador, estableciendo la separación de niños y niñas en las escuelas, alegando para ello «razones de orden moral y eficacia pedagógica».

En el franquismo, las mujeres tenían asignado un rol muy diferente al del hombre, su sitio natural estaba en el hogar, y por lo tanto su educación tenía

16. Al respecto de la coeducación, Onésimo REDONDO señalaba en la Revista Libertad, $\mathrm{N}^{\circ} 17$, de 5 de octubre de 1931, que «La coeducación o emparejamiento escolar es un crimen ministerial contra las mujeres decentes. Es un delito contra la salud del pueblo...» 
que ir dirigida a formar buenas esposas y madres. Y debido a ello tenían que recibir una formación diferenciada de los hombres, lo que se hacía, por ejemplo, recibiendo asignaturas especificas, como Hogar o Economía Doméstica; o incluso en las materias comunes, como Educación Física y Formación del Espíritu Nacional, los contenidos diferían según el sexo del alumnado. Una Orden-Circular sobre educación de las niñas, de 5 de marzo de 1938, ya señalaba: «En las escuelas de niñas, brillará la feminidad más rotunda, procurando las Maestras, con labores y enseñanzas apropiadas al hogar, dar carácter a sus escuelas, tendiendo a una contribución práctica a favor de nuestro glorioso ejercito».

Posteriormente, la Ley de Educación Primaria de 17 de julio de 1945 consolidó de forma definitiva la segregación de niños y niñas en las escuelas. En su Preámbulo se justificaba dicha decisión, señalando: «Por razones de índole moral y de eficacia pedagógica, la Ley consagra el principio cristiano de la separación de sexos en la enseñanza».

La política educativa referente a la mujer y su integración se hacía de forma diferente a la del hombre, a éste se le adjudicaba la tarea productiva, mientras que a la mujer, básicamente, se le asignaba la función reproductiva.

La enseñanza, apoyada en la construcción de los géneros, era, sin ninguna duda, totalmente sexista y discriminatoria, e impregnaba toda la sociedad, lo que abundaba en la consideración que se tenía sobre la mujer como un ser inferior y supeditado al hombre.

La educación primaria era el final de carrera para la inmensa mayoría de las mujeres, ya que muy pocas tenían la posibilidad de pasar al bachillerato, y además la formación profesional era un reducto masculino. Ni que decir tiene que la presencia de las mujeres en la Universidad era casi nula.

Incluso la mujer que se preocupaba por aprender y ser culta, era considerada poco femenina, y merecía el oportuno reproche social ${ }^{17}$. La Iglesia Católica coincidía en la condena a las mujeres independientes y críticas, defendiendo que frente a las mujeres Bachilleres, presuntuosas y sabias, debían formarse amas de casa, expertas en la práctica de su papel tradicional ${ }^{18}$.

17. La propia Sección Femenina en la publicación Libro para las Margaritas (Publicaciones de la FET de las JONS, Madrid, 1940), recomendaba: «no hay que ser nunca una niña empachada de libros, no hay que ser una intelectual. De mayores, si hay que elegir una carrera, que sea una carrera de mujer: enfermera, puericultora o maestra».

18. La Iglesia Católica compartía la idea sobre lo perniciosa que resulta la lectura para las mujeres, así, por ejemplo, P. RIAÑO CAMPO, en Formación católica de la joven (Madrid, Pía sociedad de San Pablo, 1943) mantenía que «Las malas lecturas son de dos clases; unas matan el tesoro de la fe, otras roban el tesoro de la virtud».

Feminismo/s 12, diciembre 2008, pp. 229-252 
Los libros de texto también contribuían a la diferenciación entre mujeres y hombres. Así, a la mujer sólo se la representaba en su papel de esposa y madre, realizando tareas domésticas (cosiendo, lavando, cocinando, etc.); fuera de estos trabajos domésticos, sólo aparecía en algunas publicaciones realizando faenas de tipo agrícola o aquellas profesiones que eran consideradas tradicionalmente como femeninas: maestra, enfermera o mecanógrafa. Mientras tanto, el hombre aparecía siempre trabajando fuera del hogar, en su rol de proveedor del sustento diario necesario para mantener a la familia; y una vez en el hogar, debía descansar. Llegaron a publicarse incluso ediciones diferentes de los mismos textos, o libros sólo para niñas, con la excusa de que los objetivos a alcanzar eran distintos, atendiendo a los distintos roles que mujeres y hombres debían desempeñar en la sociedad, lo que no hacía sino contribuir a diferenciar aún más los arquetipos femeninos y masculinos.

A fin de ejemplificar lo manifestado, a continuación se traen algunos textos de fragmentos de libros y revistas de la época.

1. Un complemento necesario.

A través de toda la vida, la misión de la mujer es servir. Cuando Dios hizo el primer hombre, pensó: «No es bueno que el hombre esté solo». Y formó la mujer, para su ayuda y compañía, y para que sirviera de madre. La primera idea de Dios fue el 'hombre'. Pensó en la mujer después, como un complemento necesario, esto es, como algo útil ${ }^{19}$.

2.- Gimnasia casera.

Una mujer que tenga que atender a las faenas domésticas con toda regularidad, tiene ocasión de hacer tanta gimnasia como no lo hará nunca, verdaderamente, si trabajase fuera de su casa. Solamente la limpieza y abrillantado de los pavimentos constituye un ejemplo eficacísimo, y si se piensa en los movimientos que son necesarios para quitar el polvo de los sitios altos, limpiar los cristales, sacudir los trajes, se darán cuenta que se realizan tantos movimientos de cultura física que, aun cuando no tiene como finalidad la estética del cuerpo, son igualmente eficacísimos precisamente para este fin ${ }^{20}$.

3.- Exhibiciones indecentes.

No hay que tomar el deporte como pretexto para llevar trajes escandalosos. Podemos lucir nuestra habilidad deportiva, pero no que estas habilidades sirvan para que hagamos exhibiciones indecentes. Tampoco tenemos que tomar el deporte como pretexto para independizarnos de la familia, ni para ninguna libertad, contraria a las buenas costumbres ${ }^{21}$.

19. Sección Femenina, Formación Político-Social, Primer Curso de Bachillerato. 1963.

20. Teresa, Revista de la Sección Femenina, marzo de 1961. Reportaje sin firma.

21. Sección Femenina. Economía Doméstica para Bachillerato, Comercio y Magisterio, 1968. 
4.- Señora de.

Cuando estéis casadas, pondréis en la tarjeta vuestro nombre propio, vuestro primer apellido y después la partícula 'de', seguida del apellido de vuestro marido. Así: Carmen García de Marín. En España se dice de Durán o de Peláez. Esta fórmula es agradable, puesto que no perdemos la personalidad, sino que somos Carmen García, que pertenece al señor Marín, o sea, Carmen García de Marín²2.

\section{5.- La dependencia voluntaria.}

La vida de toda mujer, a pesar de cuanto ella quiera simular -o disimular- no es más que un eterno deseo de encontrar a quien someterse. La dependencia voluntaria, la ofrenda de todos los minutos, de todos los deseos y las ilusiones, es el estado más hermoso, porque es la absorción de todos los malos gérmenes -vanidad, egoísmo, frivolidades- por el amor ${ }^{23}$.

6.- El talento creador.

Las mujeres nunca descubren nada; les falta, desde luego, el talento creador, reservado por Dios para inteligencias varoniles; nosotras no podemos hacer más que interpretar, mejor o peor, lo que los hombres nos dan hecho ${ }^{24}$.

\section{7.- La mujer sensual.}

La mujer sensual tiene los ojos hundidos, las mejillas descoloridas, transparentes las orejas, apuntada la barbilla, seca la boca, sudorosas las manos, quebrado el talle, inseguro el paso y triste todo su ser. Espiritualmente, el entendimiento se oscurece, se hace tardo a la reflexión: la voluntad pierde el dominio de sus actos y es como una barquilla a merced de las olas: la memoria se entumece. Sólo la imaginación permanece activa, para tu daño, con la representación de imágenes lascivas, que la llenan totalmente. De la mujer sensual no se ha de esperar trabajo serio, idea grave, labor fecunda, sentimiento limpio, ternura acogedora ${ }^{25}$.

8.- Sé obediente y no te quejes.

Ten preparada una comida deliciosa para cuando él regrese del trabajo. Especialmente, su plato preferido. Ofrécete a quitarle los zapatos. Habla en tono bajo, relajado y placentero (...) En cuanto respecta a la posibilidad de relaciones íntimas con tu marido, es importante recordar tus obligaciones matrimoniales: si él siente la necesidad de dormir, que sea así no le presiones o estimules la intimidad. Si tu marido sugiere la unión, entonces accede humildemente, teniendo siempre en cuenta que su satisfacción es siempre más importante que la de una mujer. Cuando alcance el momento culminante, un pequeño gemido por tu parte es suficiente para indicar cualquier goce que

22. Ibídem.

23. Medina, Revista de la Sección Femenina, 13 de agosto de 1944.

24. Pilar Primo de Rivera, 1942.

25. Padre García Figer en Medina, Revista de la Sección Femenina, 12 de agosto de 1945.

Feminismo/s 12, diciembre 2008, pp. 229-252 
hayas podido experimentar. Si tu marido te pidiera prácticas sexuales inusuales, sé obediente y no te quejes ${ }^{26}$.

Sólo a partir de la década de los sesenta podemos afirmar que empezaron a producirse algunos cambios en el modelo educativo, aunque éstos fueron del todo insuficientes.

Pero no fue hasta la Ley General de Educación de 1970 cuando se materializaron estos cambios, ya que por primera vez en esta Ley, se consagraba la igualdad de ambos sexos en el sistema escolar. Y además dicha norma también obligaba a la escolarización obligatoria de todos los niños/niñas hasta los catorce años.

\subsection{Derecho del Trabajo}

Antes incluso de acabar la guerra civil, en concreto en el año 1938, se aprobó el Fuero del Trabajo, publicado por Decreto de 9 de marzo, en el que se regulaban los derechos y deberes profesionales de los trabajadores, el cual vino a relegar a la mujer al ámbito doméstico. De esta forma, dicha norma, en un falso afán de proteccionismo paternalista, afirmaba que «en especial prohibirá el trabajo nocturno de las mujeres y niños, regulará el trabajo a domicilio y liberará a la mujer casada del taller y de la fabrica», lo que supuso eliminar en la práctica a la mujer casada del mundo laboral. Y por si fuera poco, un posterior Decreto, aprobado el 31 de diciembre de ese mismo año, afirmaba en su Introducción que «La tendencia del Nuevo Estado es que la mujer dedique su atención al hogar y se separe de los puestos de trabajo», y seguidamente en su articulo 4 establecía la «prohibición del empleo de la mujer casada, a partir de un determinado ingreso que perciba su marido».

Durante la Dictadura, el trabajo remunerado fuera del hogar fue un ámbito vedado a las mujeres, ya que el espacio que el Régimen les reservaba se situaba en el ámbito doméstico y por lo tanto cuando realizaban algún trabajo remunerado o fuera del hogar, sólo lo era de forma provisional y auxiliar al de los hombres.

Además, el Régimen aceptaba el trabajo de las mujeres pero siempre que fueran solteras, ya que una vez contraían matrimonio, debían irse, junto con la dote, con su marido, a ocuparse de su familia.

La principal ocupación de las mujeres va a estar en el servicio doméstico; o a veces, también en fábricas, pero cobrando menos salario que los hombres, y sin posibilidad de acceso a puestos de responsabilidad.

26. Sección Femenina, 1958.

Feminismo/s 12, diciembre 2008, pp. 229-252 
Hasta 1961, la mayoría de las ordenanzas laborales y normativas de trabajo en empresas publicas y privadas establecían despidos forzosos de trabajadoras al contraer matrimonio y en determinadas empresas algunos reglamentos de régimen interior prohibían a las mujeres ejercer puestos de dirección. Así, por ejemplo, la Orden del Ministerio de Trabajo de 27 de septiembre de 1939, prohibió a los «funcionarios femeninos» obtener la categoría de Jefe de Administración. Además, la mujer casada continuaba necesitando el permiso de su marido para firmar un contrato de trabajo o ejercer actividades comerciales.

Pero incluso en los casos en que la mujer podía trabajar, además de necesitar la autorización del marido, éste podía llegar a pedir para sí el derecho a cobrar el salario de su mujer.

También, por ejemplo, la mujer tenía prohibido acceder al Cuerpo de Notarios y Registradores de la propiedad, al Cuerpo Diplomático, al Ministerio de la Gobernación, etc.

Como destaca la Profesora Balaguer Callejón, «en lo laboral todas estas leyes franquistas eran sobre todo discriminatorias y proteccionistas. La mujer quedaba fuera del trabajo nocturno, de determinados puestos de trabajo y sobre todo fuera del mercado de trabajo en el momento de contraer matrimonio ${ }^{27}$.

Dicha normativa discriminatoria para la mujer se mantuvo hasta la aprobación de Ley 56/1961, de 22 de julio, de Derechos Políticos, Profesionales y de Trabajo de la Mujer, la cual supuso un avance importante, ya que prohibió toda forma de discriminación laboral en función del sexo y expresamente la discriminación salarial, (aunque en la práctica ésta siguió subsistiendo) ${ }^{28}$.

Aunque Pilar Primo de Rivera, en la presentación de dicha Ley en las Cortes, se afanaba en justificar que:

No es, ni por asomo, una ley feminista... En modo alguno queremos hacer del hombre y la mujer dos seres iguales; por naturaleza ni por fines a cumplir en la vida podrán nunca igualarse... El trabajo de la mujer es un hecho real y universal que no podemos negar ni desconocer, y precisamente basadas en

27. Balaguer CAllejon, Ma Luisa: Mujer y Constitución. La construcción jurídica del género, Madrid, Cátedra, 2005, p. 83.

28. Interesante el artículo de Celia VALIENTE FernándeZ, publicado en la revista Historia Social $\mathrm{n}^{\circ} 31,1998$, pp. 45-65, titulado «La realización del régimen franquista: la Ley de 22 de julio de 1961 sobre derechos políticos, profesionales y de trabajo de la mujer», en el que sostiene que no se emprendió dicha reforma legal por razones de índole económica, ni tampoco intentaron con ella satisfacer demandas planteadas por grupos defensores de los derechos de la mujer, ni aspiraciones en este sentido latentes en amplios sectores de la población, sino que se aprobó a instancias de la organización de mujeres del partido único del régimen, la Sección Femenina, en un intento de ganar para España cotas más altas de aceptación internacional.

Feminismo/s 12, diciembre 2008, pp. 229-252 
este hecho lo que pedimos con esta ley es que la mujer, la mujer empujada al trabajo por necesidad, lo haga en las mejores condiciones posibles ${ }^{29}$.

De ahí que la Exposición de Motivos de dicha Ley, por un lado, reconociese el principio de no discriminación por razón de sexo, aunque por otro seguía limitándose la capacidad jurídica y de obrar de la mujer trabajadora ${ }^{30}$.

Así, lo cierto es que en el artículo 1 de la mencionada ley se reconocía expresamente a la mujer «los mismos derechos que al varón para el ejercicio de toda clase de actividades políticas, profesionales y de trabajo, sin mas limitaciones que las establecidas en la presente ley», pero aunque no se dijera expresamente, dicha declaración iba dirigida exclusivamente a la mujer soltera, ya que la mujer casada tenía la limitación de la licencia marital.

Por su parte, el artículo 3 contenía una declaración general de equiparación de la mujer al varón en el derecho al acceso a los cuerpos y carreras administrativas, pero seguidamente se establecían una serie de excepciones a dicho principio general, que impedían por ejemplo el acceso de las mujeres a las Armas y Cuerpos de los Ejércitos y a cualquier instituto armado, servicio o carrera que implicara el uso de armas; asimismo se prohibía a las mujeres acceder a la carrera judicial y fiscal -salvo en las Jurisdicciones Tutelar de Menores y Laboral-, y también se les prohibía el acceso a la Marina Mercante, salvo profesionales sanitarias.

Asimismo, el artículo 4 de dicha Ley disponía que «La mujer podrá celebrar toda clase de contratos de trabajo», para seguidamente exceptuar los «trabajos, peligrosos e insalubres».

Pero además, el artículo 5, común a todos los anteriores, exigía la autorización marital expresa para el ejercicio de algunos de los derechos reconocidos en dicha ley a las mujeres, como por ejemplo, para celebrar contratos de trabajo.

Dicha Ley se complementaba con el Decreto de 26 de julio de 1957, en el que se fijaban los trabajos prohibidos a las mujeres. En la Exposición de Motivos se justificaba dicha norma haciendo referencia a «El alto concepto que en general al español merece la mujer y la atención que de manera especial debe ser puesta en evitar que un trabajo nocivo pueda perjudicar su naturaleza». Y en su artículo 1 se concretaban algunos de los trabajos prohibidos a las mujeres, entre los que se encontraban: «el engrase, limpieza, examen o reparación

29. Primo de Rivera, Pilar, Discurso en la presentación a las Cortes en 1961 de la Ley de Derechos Políticos, Profesionales y de Trabajo de la Mujer.

30. Sin embargo, el posterior Decreto de 1 de febrero de 1962, estableció tres posibilidades para las mujeres empleadas que contrajesen matrimonio: mantener el puesto de trabajo, percibir una indemnización o quedar en excedencia (p. 30). 
de las máquinas o mecanismos en marcha que resulten de naturaleza peligrosa», o «el manejo de prensas, guillotinas, cizallas, sierras de cinta o circulares, taladros mecánicos y, en general, cualquier máquina que por las operaciones que realice, las herramientas o útiles empleados o las excesivas velocidades de trabajo represente un marcado peligro de accidentes», también «cualquier trabajo que se efectúe a más de cuatro metros de altura sobre el terreno o suelo», en fin «todos aquellos trabajos que resulten inadecuados para la salud por implicar excesivo esfuerzo físico o ser perjudiciales a sus circunstancias personales».

Años más tarde y en aplicación de la Ley de 22 de julio de 1961, se aprobó el Decreto 2310/1970, de 20 de agosto, que proclamaba en su artículo $1^{\circ}$, que «La mujer tiene derecho a prestar servicios laborales en plena situación de igualdad jurídica con el hombre y a percibir por ello idéntica remuneración». Lo que pretendía dicha norma era equiparar los derechos laborales de la mujer con los del varón, haciendo desaparecer, en teoría, toda discriminación laboral por razón de sexo pero manteniendo la autorización del marido. La autorización marital para firmar un contrato de trabajo y ejercer una actividad comercial no fue abolida hasta la reforma de los Códigos Civil y de Comercio de 1975.

\section{Conclusión}

Como hemos podido comprobar las normas jurídicas vigentes durante el franquismo fueron totalmente desigualitarias, siendo el propio ordenamiento jurídico quien se encargó de amparar la sumisión de las mujeres, situando a éstas en una posición jurídica de inferioridad respecto de los hombres ${ }^{31}$.

Sin duda, el reconocimiento de la igualdad de mujeres y hombres es una exigencia de una sociedad democrática, y por lo tanto, la instauración de un régimen democrático en España y la consiguiente aprobación de una Constitución, que define su modelo de Estado como social y democrático de derecho, debía necesariamente recoger dicha premisa fundamental, como así ocurrió.

31. Al respecto resulta interesante la reflexión que realiza la Profesora Julia Sevilla al cuestionarse: «Ante estas evidencias cabe preguntarse cuál ha sido la razón de tanta discriminación y por qué las discriminaciones que hemos padecido las mujeres y que han sido las que han construido el género se han hecho desde la ley que, en teoría, había nacido para ser objetiva, general, neutra, igual para todos» (Mujeres y ciudadanía; la democracia paritaria, Valencia, Institut Universitari d'Estudis de la Dona. Universitat de Valencia, 2004).

Feminismo/s 12, diciembre 2008, pp. 229-252 
Aunque lo cierto es que en plena transición, ya se fueron produciendo algunas reformas legislativas importantes, como la Ley de Relaciones Laborales de 8 de abril de 1976, que proclamó el principio de igualdad de derechos y obligaciones laborales de trabajadoras y trabajadores, así como el principio de igualdad retributiva entre mujer y hombre a igual trabajo; la Ley 22/1978, de 26 de mayo, que reformó del Código Penal, despenalizando los delitos de adulterio y amancebamiento; y la Ley 45/1978, de 7 de octubre, que despenalizó la venta, divulgación y propaganda de los métodos anticonceptivos a los mayores de edad.

Pero fue la Constitución de 1978 la que inició el verdadero camino para eliminar la desigualdad de mujeres y hombres, fijando las bases para ello.

Así, en su artículo 14 se reconoce la igualdad de todos los españoles ante la ley, sin que pueda prevalecer discriminación alguna por razón de sexo ${ }^{32}$.

Y por su parte, el artículo 9.2 establece que «corresponde a los poderes públicos promover las condiciones para que la libertad e igualdad del individuo y de los grupos que la integran sean reales y efectivas, así como remover los obstáculos que impidan o dificulten su plenitud».

Pero la Constitución dedica además otros preceptos a proclamar la igualdad, como el artículo 23.2 que proclama que «los ciudadanos tienen derecho a acceder en condiciones de igualdad a las funciones y cargos públicos, con los requisitos que señalen las leyes»; el artículo 27.1 que afirma que «Todos tienen derecho a la educación»; el artículo 32 que establece «El derecho del hombre y de la mujer a contraer matrimonio con plena igualdad jurídica» ${ }^{33}$; el artículo 35 que consagra «el derecho y el deber al trabajo de todos los españoles, a la libre elección de profesión u oficio, a la promoción a través del trabajo y a una remuneración suficiente para satisfacer sus necesidades y las de su familia, sin que en ningún caso pueda hacerse discriminación por razón de sexo»; el artículo 39.2, que señala que «Los poderes públicos aseguran, asimismo, la protección social de los hijos, iguales estos ante la ley con inde-

32. La Diputada Revilla López, $\mathrm{M}^{\mathrm{a}}$ Teresa, en su intervención explicando su voto de dicho artículo en la Comisión de Asuntos Constitucionales y Libertades Públicas del Congreso, afirmó «Señorías, en este artículo que hemos votado afirmativamente, la mujer española adquiere, por fin la plenitud de sus derecho», añadiendo a continuación «... Pero las mujeres no vamos a dar las gracias por ello». Recogido en el libro colectivo Las mujeres parlamentarias en la legislatura Constituyente, Madrid, Cortes Generales. Ministerio de la Presidencia, 2006, p. 95.

33. El Profesor PÉREZ Royo, Javier, en su manual Curso de derecho constitucional (Madrid, Marcial Pons, 1996), sostiene que con dicho precepto «La Constitución pone fin a la situación de desigualdad jurídica que el matrimonio suponía para la mujer», p. 322. 
pendencia de su filiación, y de las madres, cualquier que sea su estado civil. La ley posibilitará la investigación de la paternidad», etc.

En base a lo previsto en la Constitución, con posterioridad a la aprobación de ésta, se produjo una intensa actividad legislativa dirigida a desarrollar el principio de igualdad, entre las que podemos destacar la aprobación de las siguientes normas: El Estatuto de los Trabajadores de 10 de marzo de 1980, que vino a declarar como derecho básico del trabajador la no discriminación para el empleo o en el empleo, por razón del sexo o estado civil, entre otras circunstancias, añadiendo que se considerarían nulos y sin efecto los preceptos reglamentarios, las cláusulas de los convenios colectivos, los pactos individuales o las decisiones de los empresarios que contuviesen discriminaciones; la Ley 11/1981, de 13 de mayo, que modificó el Código Civil en materia de filiación, patria potestad y régimen económico del matrimonio, lo que significó el reconocimiento de la igualdad de la mujer casada, tanto en la administración y disposición de los bienes gananciales, que pasaban a ser comunes para el marido y la mujer, como en el ejercicio de la patria potestad de los hijos, compartida por ambos; asimismo se introduce una nueva regulación de la filiación, estableciendo las mismas consecuencias para los hijos habidos o no dentro del matrimonio, y además se recoge la posibilidad de que el hijo, al llegar a la mayoría de edad, fijada en la Constitución en los 18 años, pueda cambiar el orden de sus apellidos; la Ley 30/1981, de 7 de julio, que modificó la regulación del matrimonio en el Código Civil y determinó el procedimiento a seguir en las causas de nulidad, separación y divorcio; la reforma del Código Penal de 1983, que despenalizó el aborto en tres supuestos: peligro para la vida o salud física o psíquica de la madre, en caso de que el embarazo sea consecuencia de una violación o que se presuma que el feto nacerá con graves taras físicas o psíquicas; la Ley Orgánica 3/1989, de 21 de junio, a partir de la cual los llamados delitos contra la honestidad: violación, abusos deshonestos, etc., pasaron a denominarse delitos contra la libertad sexual de las personas, por entender que el bien jurídico protegido era la libertad sexual y no la honestidad; la Ley 17/89, de 19 de julio, que reguló el régimen del personal militar, haciendo efectiva la incorporación de la mujer a las fuerzas armadas, etc.

Y así sucesivamente, hasta llegar a las importantes leyes aprobadas en esta última legislatura, como han sido: la Ley Orgánica 1/2004, de 28 de diciembre, de medidas de protección integral contra la violencia de genero; la Ley 39/2006, de 14 de diciembre, de Promoción de la Autonomía Personal y Atención a las personas en situación de dependencia; y la más importante de todas, la Ley Orgánica 3/2007, de 22 de marzo, para la igualdad efectiva de mujeres y hombres. 
Resulta por lo tanto muy evidente, que desde los oscuros tiempos de la Dictadura Franquista hasta la actualidad, hemos avanzado mucho en el reconocimiento de sus derechos a las mujeres; pero, evidentemente todavía no hemos alcanzado el objetivo final, que no es otro que la igualdad real y efectiva de mujeres y hombres. Para ello resulta necesario hacer avanzar el marco jurídico-legislativo ${ }^{34}$; pero las leyes no son suficientes, hace falta algo más: es imprescindible un cambio radical en la cultura de nuestra sociedad, lo cual resulta mucho más difícil.

Precisamente por esto es necesario recuperar la memoria histórica, para conocer cuál ha sido la situación jurídica de las mujeres en momentos no tan lejanos, como fue la Dictadura Franquista. Esa es una de las pretensiones de este artículo, aunque adentrarse en el estudio sobre la posición jurídica de la mujer durante el franquismo no haya sido tarea fácil, teniendo en cuenta el escaso interés que este tema ha suscitado a los investigadores del Derecho; algo que, por otro lado, suele ocurrir frecuentemente con todo lo que atañe a las mujeres.

Mas allá de los contenidos netamente jurídicos y de la voluntad de recuperar nuestra memoria histórica, como un acicate para seguir impulsando la evolución de nuestra sociedad, este artículo pretende despertar la reflexión de quien lo lea acerca del hecho innegable de que el papel de las mujeres históricamente siempre ha estado oculto bajo la ideología patriarcal dominante durante siglos, una ideología que ha minimizado el trabajo realizado por éstas, invisibilizándolas, negándoles incluso sus derechos básicos como ciudadanas. Aunque, en muchas ocasiones esta realidad incuestionable se olvide, se evite o se niegue, tratando de encubrir la historia, lo cual debería resultar inaceptable.

34. Muy interesante la conclusión a la que llega la profesora $\mathrm{M}^{\mathrm{a}}$ del Mar Esquembre Valdes, en su artículo "Genero y Ciudadanía, Mujeres y Constitución», Feminismo/s, 8 (Mujeres $y$ derecho), diciembre 2006, pp. 35-51, donde sostiene que «Las mujeres accedimos al ámbito de toma de decisiones con las Constituciones contemporáneas (del Estado social), pero nuestras reivindicaciones se han ido atendiendo gradualmente en diversos instrumentos normativos de carácter infraconstitucional desde una base sumamente frágil, de tal forma que su afianzamiento y refuerzo requiere de su inclusión en la norma suprema que articula la convivencia, pues solo así se pueden evitar riesgos involucionistas ante nuevos desafíos ligados al fenómeno de la globalización, no sólo de carácter económico, sino también ideológico y avanzar en la consecución de una verdadera democracia». 